Artigo

\title{
Climatologia no Entorno da Central Nuclear de Angra dos Reis, RJ
}

\author{
João Batista Araujo Figueiredo ${ }^{1}$, Chou Sin Chan $^{2}$, Claudine Pereira Dereczynski ${ }^{1}$, \\ André de Arruda Lyra ${ }^{2}$, Pedro Paulo de Lima e Silva Filho ${ }^{3}$, Patrícia Moço Princisval Almeida ${ }^{3}$ \\ ${ }^{1}$ Departamento de Meteorologia, Centro de Ciências Matemáticas e da Natureza, \\ Instituto de Geociências, Universidade Federal do Rio de Janeiro, Rio de Janeiro, RJ, Brasil. \\ ${ }^{2}$ Centro de Previsão do Tempo e Estudos Climáticos, Instituto Nacional de Pesquisas Espaciais, \\ Cachoeira Paulista, SP, Brasil. \\ ${ }^{3}$ Diretoria de Radioproteção e Segurança Nuclear, Comissão Nacional de Energia Nuclear, \\ Rio de Janeiro, RJ, Brasil.
}

Recebido: 30/11/2015 - Aceito: 08/03/2016

\begin{abstract}
Resumo
Este trabalho tem por objetivo caracterizar os ciclos diurno e sazonal médios no entorno da Central Nuclear de Angra dos Reis. As condições médias são derivadas de dados horários, do período de janeiro de 2005 a dezembro de 2012. O local conta com quatro torres A, B, C e D. A Torre A mede vento e temperatura do ar a 10, 60 e $100 \mathrm{~m}$ e também precipitação, enquanto as demais torres medem somente vento a $15 \mathrm{~m}$ de altura. A atmosfera apresenta condições predominantemente estáveis ao longo do dia, com redução a partir das 6 e $7 \mathrm{~h}$, sendo que condições instáveis predominam entre às 8 e $16 \mathrm{~h}$ no verão e primavera. Os ventos da região são predominantemente fracos, a maior frequência ocorre nas intensidades entre 1,5 e $2 \mathrm{~m} / \mathrm{s}$. O mínimo de intensidade dos ventos a $10 \mathrm{~m}$ ocorre no momento da entrada da brisa marítima, às $9 \mathrm{~h}$. Os ventos catabáticos produzem um forte cisalhamento vertical dos ventos na região. Nas demais torres a máxima intensidade ocorre entre 13 e $15 \mathrm{~h}$ local. Ventos mais intensos e chuvas mais intensas foram registrados no outono (MAM), o que sugere ser este o período de tempestades mais intensas.
\end{abstract}

Palavras-chave: Angra dos Reis, brisa, temperatura do ar, vento, precipitação, ciclo diurno, ciclo sazonal.

\section{Angra Nuclear Power Plant Climatology, Rio De Janeiro}

\begin{abstract}
The objective of this work is to characterize the mean diurnal and seasonal cycles around the Nuclear Power Plant in Angra dos Reis, RJ. The averages were taken for an hourly dataset in the period January 2005 and December 2012, based on four towers. Tower A measures air temperature and wind at three levels: 10, 60, and $100 \mathrm{~m}$. Towers B, C, and D measure only wind at $15 \mathrm{~m}$. The diurnal cycle of static stability show stable conditions prevailing during most of the day. The static stability starts to reduce at about 6 and 7 LT, whereas the most unstable conditions occur between 8 and 16 LT. Winds are predominantly weak, with the most frequent intensity between 1.5 and $2 \mathrm{~m} / \mathrm{s}$. The minimum of $10-\mathrm{m}$ winds occur when the sea breeze starts, at about 9 LT. The catabatic winds are a strong feature of the Tower A-10 $\mathrm{m}$ winds, and reveals strong vertical shear. The other towers do not show a clear minimum in the diurnal cycle of the wind, but the maximum occurs between 13 and 15 LT. Stronger wind and heavier precipitations were registered in autumn, MAM, which suggests the period of stronger storms.
\end{abstract}

Keywords: sea breeze, air temperature, wind, precipitation, diurnal cycle, seasonal cycle, Angra dos Reis.

\section{Introdução}

A Central Nuclear Almirante Álvaro Alberto (CNAAA), onde se localizam as usinas nucleares Angra $1 \mathrm{e}$ Angra 2 e futuramente a usina Angra 3, situa-se no muni- cípio de Angra dos Reis, litoral sul do Estado do Rio de Janeiro, numa região de topografia complexa. Angra dos Reis é caracterizada pelo intenso contraste entre as regiões montanhosas da Serra do Mar e áreas litorâneas, o que gera circulações atmosféricas de escala local, tais como as brisas

Autor de correspondência: Claudine Pereira Dereczynski, claudine@acd.ufrj.br. 
terrestre/marítima e de vale/montanha. Uma previsão acurada da intensidade e direção do vento na região de estudo é de extrema importância no sentido de compor uma ferramenta que auxilie o sistema de emergência da CNAAA, estimando as direções e intensidades de propagação da radiação em caso de acidente com vazamentos em uma das três usinas.

Como etapa prévia à avaliação de previsões meteorológicas geradas por modelos numéricos de alta resolução sobre a região em estudo, é importante elaborar uma climatologia através de dados observacionais a fim de compreender os efeitos da complexa topografia na circulação local. $\mathrm{Na}$ área da CNAAA estão instaladas quatro Torres Meteorológicas (A, B, C e D) que medem o vento e a temperatura do ar em três níveis de altura na Torre $\mathrm{A}(10 \mathrm{~m}, 60 \mathrm{~m}$ e $100 \mathrm{~m}$ ) e apenas o vento a $15 \mathrm{~m}$ de altura nas demais Torres. Tais dados, além de totais pluviométricos diários, foram gentilmente cedidos pela Eletronuclear e são utilizados neste trabalho.

De acordo com Rosa (2003) na área em estudo as escarpas da Serra do Mar chegam junto ao litoral, e num raio de $80 \mathrm{~km}$ em torno da CNAAA são encontradas montanhas com altitudes superiores a $2500 \mathrm{~m}$ e platôs bastante amplos acima de $1300 \mathrm{~m}$. A camada de inversão térmica suspensa sobre o mar e o litoral é encontrada ao nível dos platôs mais elevados e suprime os movimentos convectivos, impedindo a ascenção dos poluentes e da umidade do ar para as camadas mais elevadas da atmosfera (Rosa, 2003). A camada de ar estável, suspensa acima da camada de mistura litorânea, encosta-se nas serras e no planalto uma outra camada de mistura se forma, assim como uma nova estratificação das camadas de ar (Rosa, 2003).

Em Oliveira Junior et al. (2010) encontra-se uma climatologia da estabilidade atmosférica na região da CNAAA utilizando Número de Richardson Bulk (RiB) para os dados da Torre A no período de 2002 a 2005 (4 anos). Seus resultados mostram que predomina na região, entre os níveis de 100 e $10 \mathrm{~m}$, condição de atmosfera estaticamente estável (79\% dos casos), seguida da instável, $17 \%$ e neutra em apenas $4 \%$ dos casos. Os autores ressaltam a baixa capacidade da atmosfera na região em estudo para dispersar poluentes.

Uma climatologia do vento na CNAAA é apresentada por Oliveira Junior (2008) para o período de 1982-2001 (20 anos), mostrando que predominam ventos fracos na região (inferior a $2 \mathrm{~m} / \mathrm{s}$ ) durante todo o ano. $\mathrm{O}$ horário de ocorrência da máxima intensidade do vento varia entre $13 \mathrm{~h}$ (brisa marítima) até $1 \mathrm{~h}$ (vento de encosta). A ocorrência da mínima intensidade do vento para a Torre A a $10 \mathrm{~m}$ de altura e para Torre D a $15 \mathrm{~m}$ de altura está associado aos horários de transição dos regimes de escoamento do vento de encosta para brisa marítima (entre 8 e 9 h) e da brisa terrestre para o regime de encosta (entre 17 e $18 \mathrm{~h}$ ) e nas demais torres o período inicia na madrugada até as primeiras horas da manhã. Com relação a direção do vento,
Oliveira Junior (2008) encontrou predominância na Torre A a $10 \mathrm{~m}$ de altura e na Torre B, vento de $\mathrm{N}$; na Torre A a 60 e $100 \mathrm{~m}$ de altura vento na direção SW; na Torre C, vento de NNW e na Torre D vento de W.

Com objetivo de relacionar a precipitação a deslizamentos na região de Angra dos Reis, Soares (2006) construiu inicialmente em seu trabalho uma climatologia da precipitação a partir dos dados observados na CNAAA no período de 1980 a 2004 (25 anos). Seus resultados mostram que a precipitação mensal na área em estudo varia entre $68,8 \mathrm{~mm}$ em julho a $264,3 \mathrm{~mm}$ em janeiro. O verão é a estação mais chuvosa $(239,8 \mathrm{~mm} / \mathrm{mês})$, seguida da primavera $(180,43 \mathrm{~mm} / \mathrm{mês})$, outono $(177,6 \mathrm{~mm} / \mathrm{mês})$ e por último o inverno (70,4 mm/mês).

O clima na área em estudo resulta da interação de diversos sistemas meteorológicos com distintas escalas espaciais e temporais. Na maior parte no ano atua o Anticiclone Subtropical do Atlântico Sul (ASAS), promovendo condições de estabilidade e ventos calmos de quadrante norte na região (Satyamurty et al., 1998). Essa situação de estabilidade é perturbada pela passagem de sistemas transientes pela região. Em especial, durante os meses de novembro a março é comum o estabelecimento da Zona de Convergência do Atlântico Sul (ZCAS) que se caracteriza por uma banda de nebulosidade convectiva, estendendo-se em geral desde a Amazônia, até o Oceano Atlântico, numa direção noroeste-sudeste (Kousky, 1988). A ZCAS é um sistema frequente no verão da Região Sudeste com uma média de 7 eventos (no período de 1996-2013) observados a cada ano (Dereczynski et al., 2015). Dos transientes, os sistemas frontais (SFs) são os mais frequentes. De acordo com Oliveira (1986), passam em média na banda latitudinal entre 25 e $20^{\circ} \mathrm{S}$ durante a primavera e verão, respectivamente $4 \mathrm{e}$ 3 sistemas frontais (SFs) por mês e todos conseguem organizar a convecção no interior do continente, enquanto no inverno dos 4 SFs apenas 1 provoca precipitação. Além desses sistemas de escala sinótica, destacam-se na região os Sistemas Convectivos de Mesoescala (SCMs) formados essencialmente por núcleos individuais ou aglomerados de nuvens cumoluninbus, responsáveis por condições de tempo severo como rajadas de vento, chuvas na forma de pancadas, relâmpagos e trovões e, em alguns casos, precipitação na forma de granizo. Em Siqueira e Marques (2008) ressalta-se que os SCMs de origem frontal são bem mais frequentes do que os de origem não frontal que é um indicativo da importância das frentes frias na organização da nebulosidade convectiva sobre a Região Sudeste do Brasil ao longo do ano. Na região em estudo atuam também as brisas marítima/terrestre e de vale/montanha que interagem enfraquecendo ou intensificando os ventos na região da CNAAA (Oliveira Junior, 2008).

De acordo com Leão e Pereira (1976) as Serras do Mar e da Mantiqueira formam uma barreira às correntes de ar geradas pelo centro do ASAS e pelas brisas maríti$\mathrm{ma} /$ terrestre e de vale/montanha, e dessa forma, a estrutura 
da camada limite atmosférica (CLA) na região pouco se assemelha ao encontrado na literatura. $\mathrm{Na}$ Central Nuclear de Angra dos Reis coexiste uma interface oceano-continente-montanha que altera drasticamente o comportamento da atmosfera local, principalmente os sistemas de brisas (Oliveira Junior, 2008).

Neste trabalho, dados horários de vento e temperatura do ar coletados nas quatro torres meteorológicas e dados de precipitação observados na área central da CNAAA são utilizados para construir uma climatologia de oito anos (janeiro de 2005 a dezembro de 2012) da região. Objetiva-se descrever o comportamento dos ciclos diurnos e anuais do vento, da temperatura do ar, da estabilidade atmosférica e da precipitação na região da CNAAA. Os resultados deste trabalho serão utilizados futuramente para avaliação das previsões do modelo regional Eta (Mesinger et al., 2012).

$\mathrm{Na}$ seção 2 encontra-se a metodologia e os dados utilizados no trabalho. Na seção 3 apresentam-se os resul- tados das análises climatológicas da temperatura do ar, estabilidade estática da atmosfera, vento e precipitação. As conclusões estão na seção 4 .

\section{Metodologia e Dados}

O conjunto de dados utilizados neste trabalho, gentilmente cedidos pela Eletronuclear, referem-se às observações horárias de temperatura do ar e vento coletadas no período de janeiro de 2005 a dezembro de 2012 ( 8 anos) nas Torres A, B, C e D instaladas na região da CNAAA (Fig. 1). Os dados horários de precipitação, do mesmo período, foram coletados próximos à Torre A. A localização das Torres, assim como as variáveis observadas em cada uma delas estão apresentados na Tabela 1. A Torre A é a única que mede as variáveis temperatura do ar, direção e intensidade do vento em três níveis de altura (10, 60 e 100 m). As demais torres, registram somente a intensidade e direção do vento a $15 \mathrm{~m}$ de altura. A Torre A está situada na Praia de

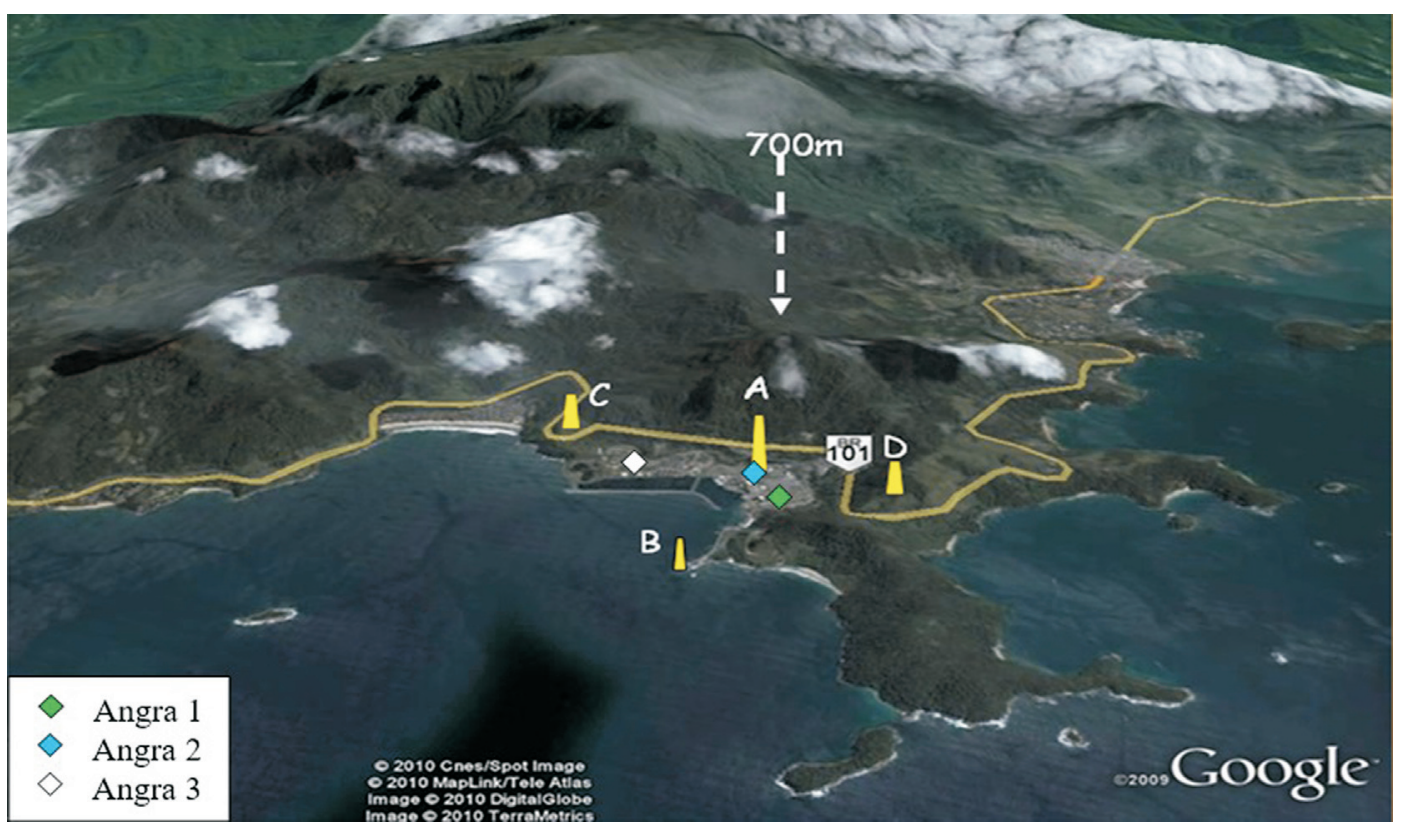

Figura 1 - Localização das torres meteorológicas A, B, C e D da Usina Nuclear de Angra dos Reis (CNAAA) sobre uma imagem da região obtida no sítio http://www.google.com.br/intl/pt-BR/earth/.

Tabela 1 - Localização das Torres A, B, C e D na Usina Nuclear de Angra dos Reis (CNAAA) e as variáveis utilizadas neste trabalho.

\begin{tabular}{|c|c|c|c|c|c|}
\hline \multirow[t]{2}{*}{ Torres } & \multicolumn{3}{|c|}{ Localização real das Torres } & \multirow[t]{2}{*}{ Variáveis observadas } & \multirow[t]{2}{*}{ Altura (m) } \\
\hline & Lat $\left({ }^{\circ} \mathrm{S}\right)$ & Lon $\left({ }^{\circ} \mathrm{W}\right)$ & Altitude (m) & & \\
\hline \multirow[t]{4}{*}{ A } & 23,01 & 44,46 & 40 & Temperatura do $\operatorname{ar}\left({ }^{\circ} \mathrm{C}\right)$ & 10,60 e 100 \\
\hline & & & & Intensidade do vento $(\mathrm{m} / \mathrm{s})$ & \\
\hline & & & & Direção do vento (graus) & \\
\hline & & & & Precipitação (mm/dia) & \\
\hline B & 23,02 & 44,46 & 12 & Intensidade do vento $(\mathrm{m} / \mathrm{s})$ & 15 \\
\hline $\mathrm{C}$ & 23,01 & 44,47 & 166 & Direção do vento (graus) & \\
\hline $\mathrm{D}$ & 23,01 & 44,45 & 290 & & \\
\hline
\end{tabular}


Itaorna, na área de acesso à CNAAA. A Torre B localiza-se na ponta da Praia de Itaorna. A Torre C fica no Morro do Urubu e a Torre D encontra-se no platô do Morro da Torre do Microondas.

Foram estabelecidos limiares para cada variável a fim de excluir das séries os dados espúrios. Além disso, as observações nas Torres B e D durante os meses de abril e maio de 2009 não estão disponíveis. Do total de 2922 dias no período 01/01/2005 a 31/12/2012 (8 anos), considerando-se 24 horas por dia, resultariam em 70128 dados para cada variável em cada uma das Torres. No entanto, a série mais longa, ventos a $10 \mathrm{~m}$ de altura da Torre A, contém 69826 dados $(99,57 \%$ do total $)$ e a série mais curta, vento na Torre D, é composta por 67882 dados (96,80\% do total).

Uma análise da estabilidade estática da atmosfera, realizada a partir dos dados da Torre A, é feita calculando-se o gradiente vertical de temperatura do ar entre os níveis 60-10 m e 100-60 m, como apresentado na Eq. (1)

$$
\gamma=-\frac{d T}{d z}
$$

e comparando-o com os conhecidos valores do gradiente adiabático seco (aproximadamente $10{ }^{\circ} \mathrm{C} / \mathrm{km}$ ) e do gradiente adiabático úmido (aproximadamente $4,5^{\circ} \mathrm{C} / \mathrm{km}$ nos baixos níveis). A análise, assim como descrita em Wallace e Hobbs (2006), leva em conta o seguinte:

a) Caso $\gamma<\frac{4,5^{\circ} \mathrm{C}}{\mathrm{km}}$ a atmosfera é dita "Absolutamente Estável”, pois ele será menor do que o gradiente adiabático úmido $\left(4,5^{\circ} \mathrm{C} / \mathrm{km}\right)$, e portanto, também menor do que o gradiente adiabático seco $\left(10^{\circ} \mathrm{C} / \mathrm{km}\right)$;

b) Caso $\gamma>\frac{10^{\circ} \mathrm{C}}{\mathrm{km}}$ a atmosfera é dita "Absolutamente Instável", pois ele será maior do que o gradiente adiabático seco $\left(10^{\circ} \mathrm{C} / \mathrm{km}\right)$, e portanto, também maior do que o gradiente adiabático úmido $\left(4,5^{\circ} \mathrm{C} / \mathrm{km}\right)$ e

c) Caso $\frac{4,5^{\circ} \mathrm{C}}{\mathrm{km}}<\gamma<\frac{10^{\circ} \mathrm{C}}{\mathrm{km}}$, a atmosfera é dita "Condicionalmente Instável", significando que se o ar estável e não saturado for de algum modo levantado até um nível onde se torne saturado, poderá resultar em instabilidade.

Em todo o trabalho considera-se como o período de verão o trimestre dezembro-janeiro-fevereiro, para o outono os meses de março-abril-maio, como inverno junhojulho-agosto e primavera os meses de setembro-outubronovembro.

\section{Resultados}

Nesta seção apresentam-se os resultados das climatologias horárias da temperatura do ar, da estabilidade estática, do vento e da precipitação.

\subsection{Temperatura do ar}

A Fig. 2 apresenta a climatologia sazonal do ciclo diurno da temperatura do ar observada na Torre A para os três níveis de altura $(10 \mathrm{~m}, 60 \mathrm{~m}$ e $100 \mathrm{~m})$. Observa-se, como o esperado, temperaturas mais elevadas durante os meses de verão e mais amenas no inverno. As maiores temperaturas do dia situam-se entre 26 e $27^{\circ} \mathrm{C}\left(19\right.$ e $\left.20^{\circ} \mathrm{C}\right)$ no verão (inverno) entre os três níveis de altura da Torre $\mathrm{A}$, ou seja, uma amplitude térmica anual em torno de $7^{\circ} \mathrm{C}$. No outono as temperaturas são mais elevadas do que na primavera. No ciclo diurno destaca-se a redução da temperatura no período noturno, atingindo um mínimo antes do nascer do Sol, em torno de $6 \mathrm{~h}$, e um aumento ao longo do dia, cerca de duas horas após o horário de máximo recebimento da radiação solar, aproximadamente entre 14 e 15 h. A redução da temperatura com a altura também é evidente na figura, observando-se que durante todo o ano a temperatura a $60 \mathrm{~m}$ é aproximadamente $0,7^{\circ} \mathrm{C}$ maior do que a temperatura a $100 \mathrm{~m}$ durante todo o dia, o que justifica-se pelo fato da atmosfera ser aquecida por baixo. Como o ar é mau condutor de calor, no nível mais baixo $(10 \mathrm{~m})$ a amplitude térmica é maior do que nos demais níveis (60 e $100 \mathrm{~m}$ ), influenciado pelos processos de troca de calor que são mais eficientes próximo ao solo, com ganho de radiação de onda longa (ROL) durante o dia e perda no período noturno e na madrugada. Resulta então, uma amplitude térmica média diária nos meses de verão de aproximadamente $3,0{ }^{\circ} \mathrm{C}$ para o nível de $10 \mathrm{~m}$ e aproximadamente a metade (cerca de $1,5^{\circ} \mathrm{C}$ ) para os outros dois níveis de temperatura. Tais valores de amplitude térmica diária são pequenos quando comparados com a amplitude térmica anual e também com amplitudes térmicas diárias de estações localizadas em regiões afastados de grandes corpos de água. No nível mais próximo ao solo $(10 \mathrm{~m})$ a temperatura é em geral mais baixa do que nos demais níveis durante a noite e a madrugada, principalmente no inverno, já que o ar em contato com a superfície é resfriado por condução e por perda radiativa. Durante o dia a temperatura do ar a $10 \mathrm{~m}$ de altura eleva-se acima dos valores encontrados no níveis de 60 e $100 \mathrm{~m}$, também devido as trocas de calor com a superfície.

Na Fig. 3 encontra-se a distribuição de frequência de todos os valores de temperatura do ar observados na Torre A nos três níveis. Observa-se que os picos de máxima frequência de ocorrência oscilam entre 20 e $21{ }^{\circ} \mathrm{C}$ no inverno, 22 e $23{ }^{\circ} \mathrm{C}$ na primavera, 24 e $25^{\circ} \mathrm{C}$ no outono e finalmente entre 25 e $26{ }^{\circ} \mathrm{C}$ no verão. A variabilidade sazonal é mais importante do que a variabilidade observada entre os três níveis de altura. É interessante notar que os picos de maior frequência de ocorrência para a altura de 60 m estão deslocados para a direita em relação ao nível de $10 \mathrm{~m}$, exceto na primavera. Apesar desse aspecto ser mais evidente nessa figura do que na anterior, observa-se na Fig. 2 que de fato, durante a noite e a madrugada ocorrem maiores valores de temperatura do ar no nível de $60 \mathrm{~m}$ do que a $10 \mathrm{~m}$ de altura. Na primavera as temperaturas a $60 \mathrm{~m}$ 
(a) Verão

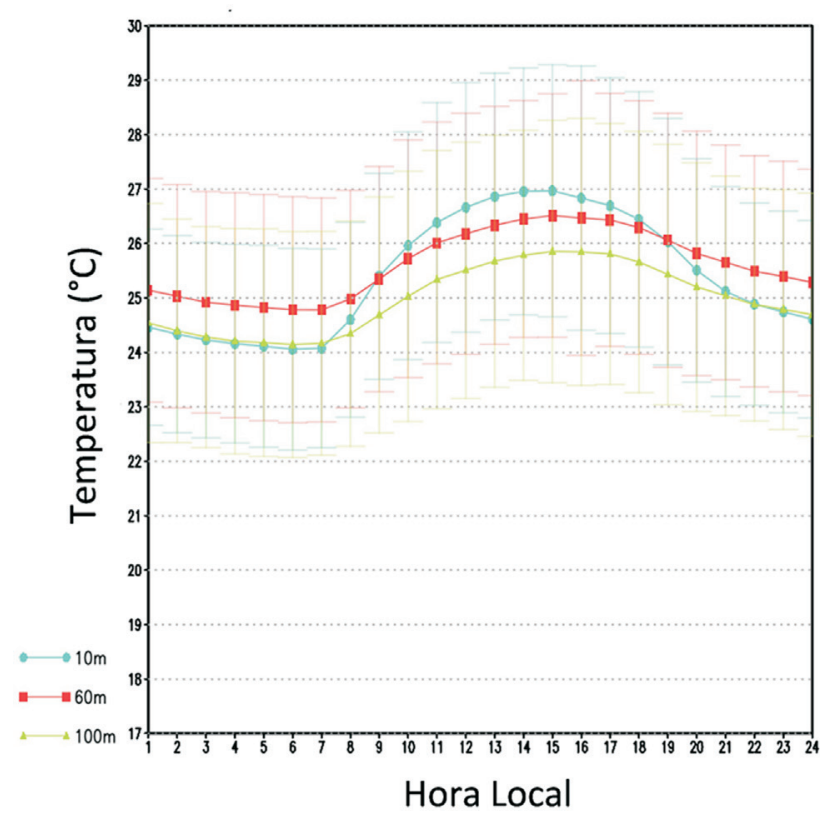

(c) Inverno

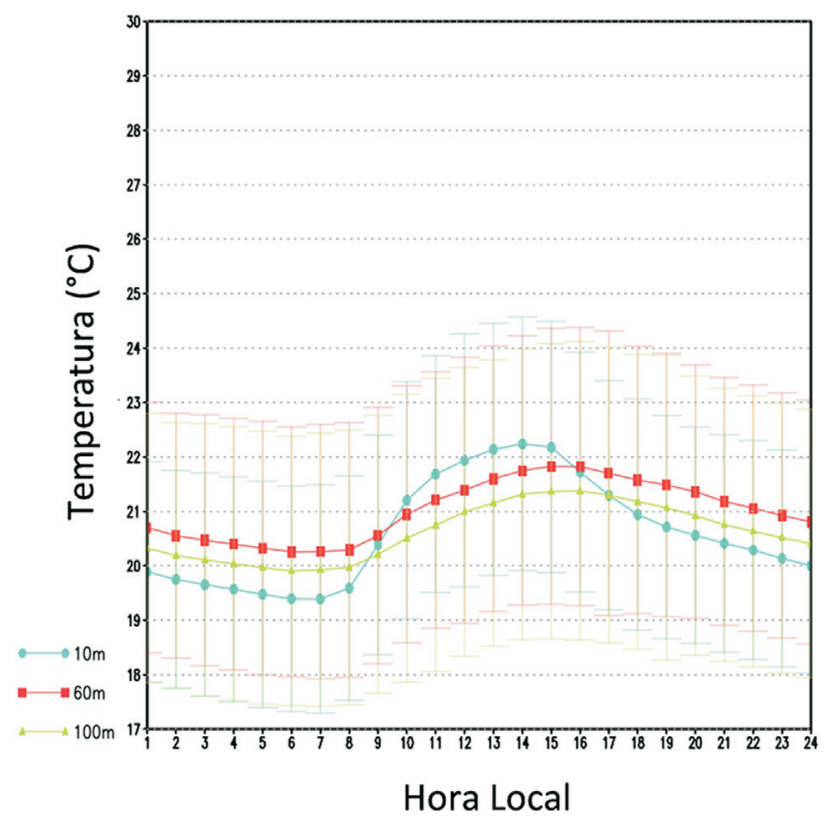

(b) Outono

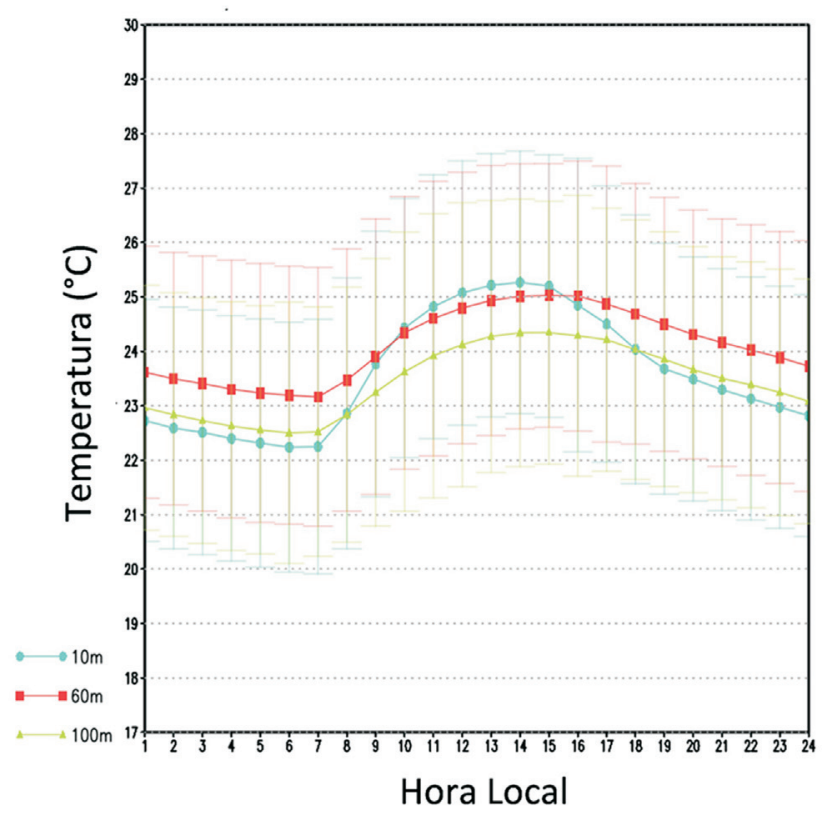

(d) Primavera

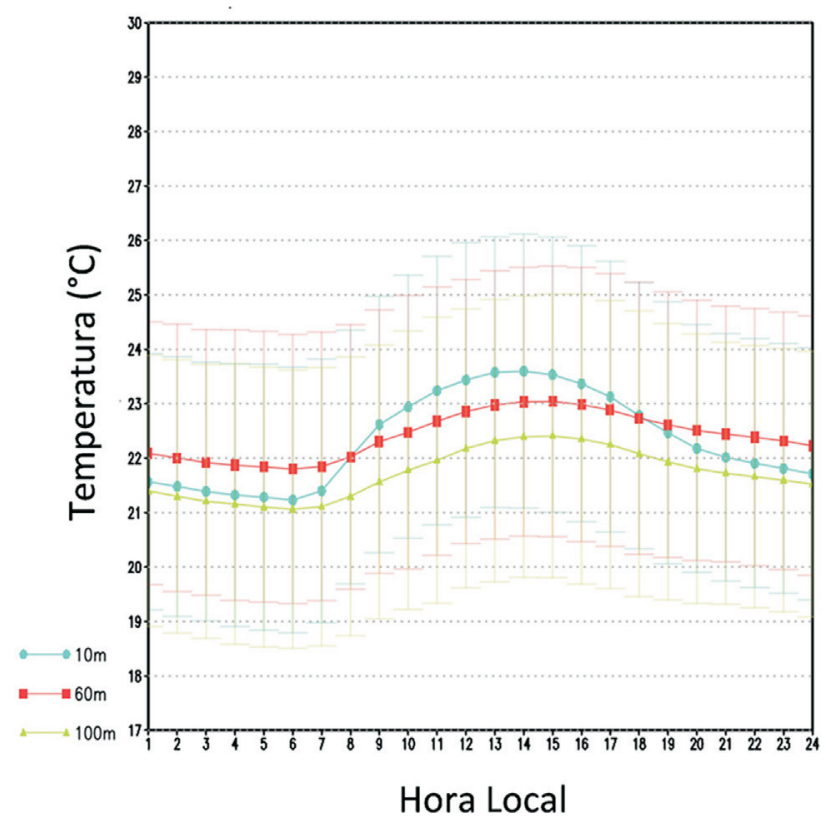

Figura 2 - Temperaturas médias e desvio padrão horários a $10 \mathrm{~m}$ (azul), 60 m (vermelho) e $100 \mathrm{~m}$ (verde) na Torre A para: (a) verão, (b) outono, (c) inverno e (d) primavera. Climatologia do período de janeiro de 2005 a dezembro de 2012 ( 8 anos).

de altura só superam as temperaturas a $10 \mathrm{~m}$ no período de $20 \mathrm{~h}$ até $7 \mathrm{~h}$, enquanto no inverno isso ocorre num período mais longo, entre 16 e $9 \mathrm{~h}$.

\subsection{Estabilidade atmosférica estática}

A estabilidade atmosférica é importante para identificar se uma parcela de ar ao ser levantada, continuará a subir ou não, quando cessar a causa do movimento. Por exemplo, em uma situação na qual a parcela de ar é forçada a subir ao encontrar uma montanha, caso ela esteja mais fria do que a atmosfera ao seu redor, ela retorna a sua posição original e a atmosfera é dita estável. Neste caso, as nuvens serão pouco espessas, com bases e topos planos (nuvens estratiformes). Por outro lado, caso a parcela seja mais quente do que a atmosfera ao seu redor, ela se tende a subir cada vez mais e a se deslocar para longe de sua posição original, e a atmosfera é dita instável. As nuvens, se forma- 


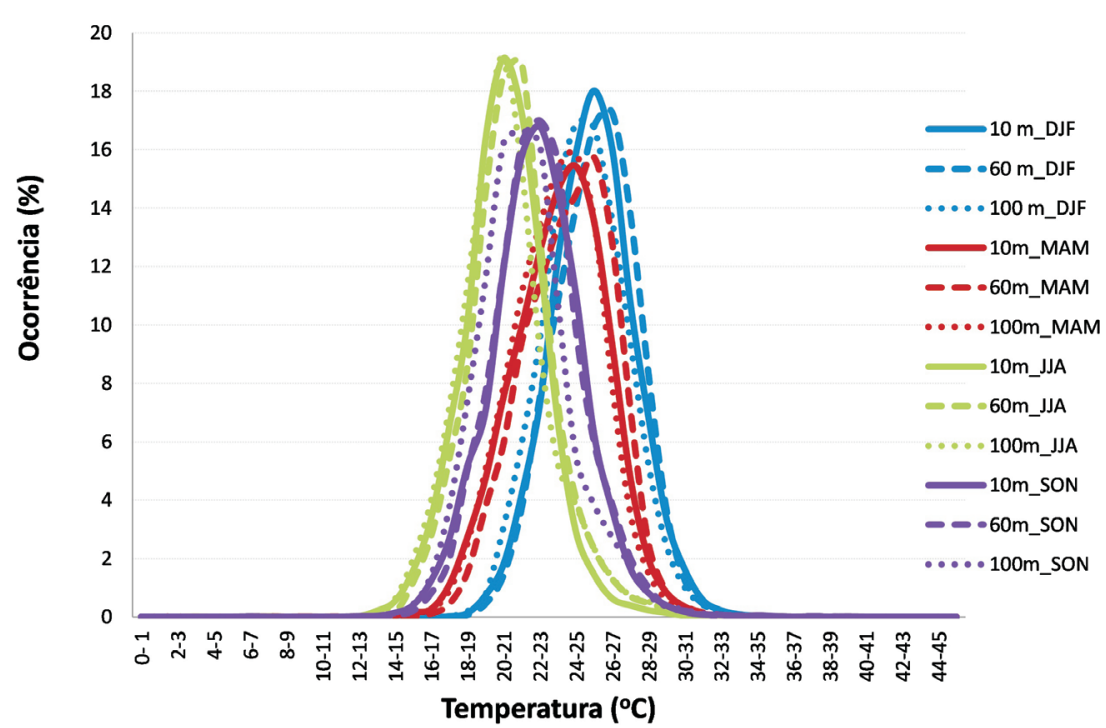

Figura 3 - Distribuição de frequência relativa da temperatura do ar na Torre A nas alturas de: a) $10 \mathrm{~m}$, b) $60 \mathrm{~m} \mathrm{e} \mathrm{c)} 100 \mathrm{~m}$ para o verão, outono, inverno e primavera. Climatologia do período de janeiro de 2005 a dezembro de 2012 ( 8 anos).

das, serão do tipo cumuliformes, com grande desenvolvimento vertical (Hess, 1959).

A Fig. 4 apresenta os valores do gradiente vertical de temperatura do ar para a Torre A, calculado através da Eq. (1), para as camadas $60-10 \mathrm{~m}, 100-60 \mathrm{~m}$ e $100-10 \mathrm{~m}$ nas quatro estações do ano. Os limiares de 4,5 e $10{ }^{\circ} \mathrm{C} / \mathrm{km}$ aparecem em destaque na figura a fim de facilitar a visualização de situações em que a atmosfera é absolutamente estável (valores inferiores a $4,5{ }^{\circ} \mathrm{C} / \mathrm{km}$ ), absolutamente instável (valores superiores a $10^{\circ} \mathrm{C} / \mathrm{km}$ ) e de instabilidade condicional (valores entre 4,5 e $10{ }^{\circ} \mathrm{C} / \mathrm{km}$ ). Nota-se na Fig. 4 que na noite e na madrugada predominam condições de estabilidade (gradiente térmico entre -20 e $-10{ }^{\circ} \mathrm{C} / \mathrm{km}$ ) durante todo o ano na camada mais baixa, entre $60-10 \mathrm{~m}$, característico da inversão de temperatura. Tal estabilidade é interrompida durante o aquecimento diurno, quando a atmosfera torna-se condicionalmente instável (no verão, outono e inverno) ou instável (na primavera). Na camada superior, entre 100-60 m, predominam condições de instabilidade absoluta na maior parte do ano, exceto no inverno quando se observa também condições de instabilidade condicional durante a madrugada. Considerando-se toda a camada (100-10 m) o comportamento do gradiente vertical de temperatura é praticamente o mesmo daquele apresentado para camada mais baixa (60-10 m), exceto que o módulo do gradiente térmico é menor, variando entre -6 a $2{ }^{\circ} \mathrm{C} / \mathrm{km}$. A camada de 60-100 m praticamente não possui ciclo diurno.

\subsection{Vento}

Na Fig. 5 apresenta-se a climatologia sazonal da intensidade e da direção do vento para os três níveis da Torre A. Observa-se nas quatro estações do ano e nos três níveis

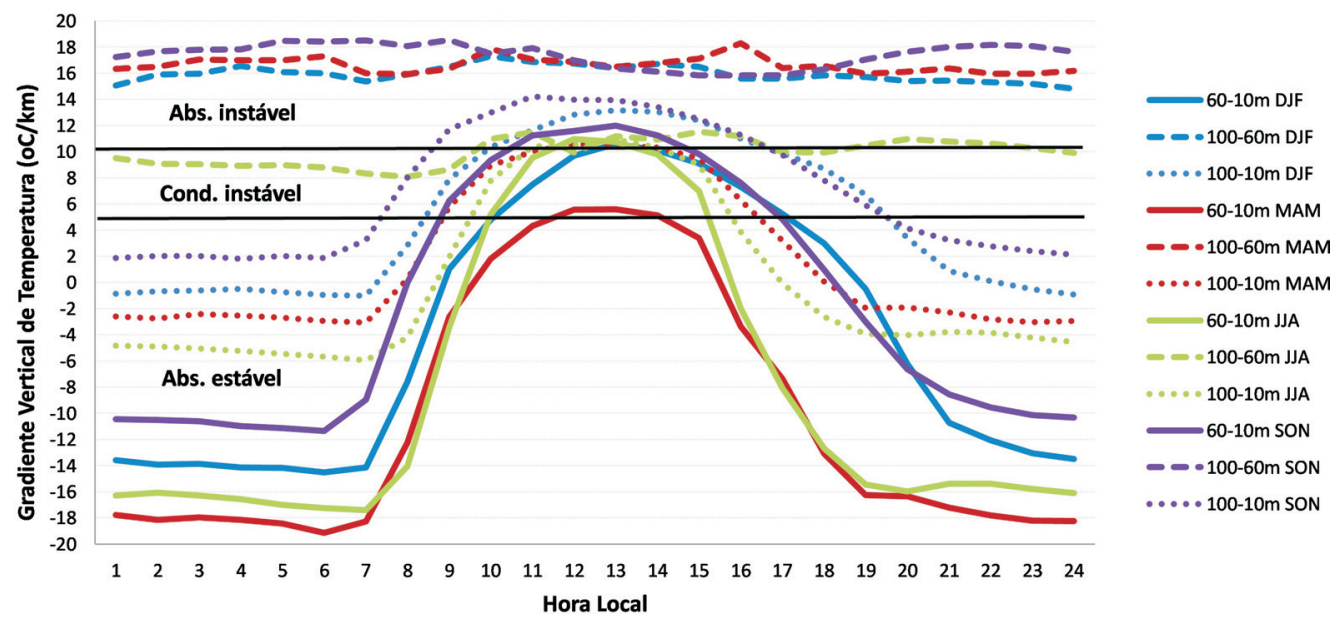

Figura 4 - Gradiente vertical de temperatura do ar $\left({ }^{\circ} \mathrm{C} / \mathrm{km}\right)$ para os níveis $100-60 \mathrm{~m}$ e $60-10$ m para o verão (DFJ), outono (MAM), inverno (JJA) e primavera (SON). Climatologia do período de janeiro de 2005 a dezembro de 2012 (8 anos). 
que a intensidade do vento começa a aumentar entre 8 e $9 \mathrm{~h}$ da manhã, atinge um máximo em torno de $15 \mathrm{~h}$ e a partir desse horário começa a enfraquecer. Isso mostra que o efeito da brisa marítima, caracterizada por ventos mais intensos do que a brisa terrestre (Ayoade, 2006), é sentido até o nível de $100 \mathrm{~m}$ de altura. Durante a noite e a madrugada nota-se ventos mais intensos, assim como temperaturas mais baixas (Fig. 2) no nível de 10 m, em relação aos demais níveis. Isso pode estar relacionada a interação entre a brisa terrestre e o vento catabático que é mais eficiente nos baixos níveis. No nível mais baixo $(10 \mathrm{~m})$ destaca-se também a mudança na direção do vento que sopra de quadrante norte na noite e madrugada e de quadrante sul nos períodos da manhã e da tarde. Nos níveis de 60 e $100 \mathrm{~m}$ o efeito das brisas parece afetar mais a intensidade do que a direção do vento. Analisando o horário da mudança na

direção do vento no nível de $10 \mathrm{~m}$, nota-se que no verão (inverno) a brisa marítima começa a atuar as $9 \mathrm{~h}(10 \mathrm{~h})$ e se prolonga até as $19 \mathrm{~h}(15 \mathrm{~h})$.

A comparação da climatologia sazonal dos ventos nos baixos níveis nas Torres A, B, C e D é apresentada na Fig. 6. É importante lembrar que as Torres estão localizadas em altitudes e regiões distintas (Tabela 1 ). Nota-se que no horário de atuação da brisa marítima o vento é mais intenso na Torre B devido a sua localização mais próxima ao oceano, onde o atrito não é tão importante. Nos demais horários do dia as intensidades dos ventos nas quatro torres não são muito distintas. Com relação a direção dos ventos, observa-se que nas Torres A e D (Torres B e C) os ventos são predominantemente de sudoeste (sudeste) no período diurno.

\section{(a) Verão}

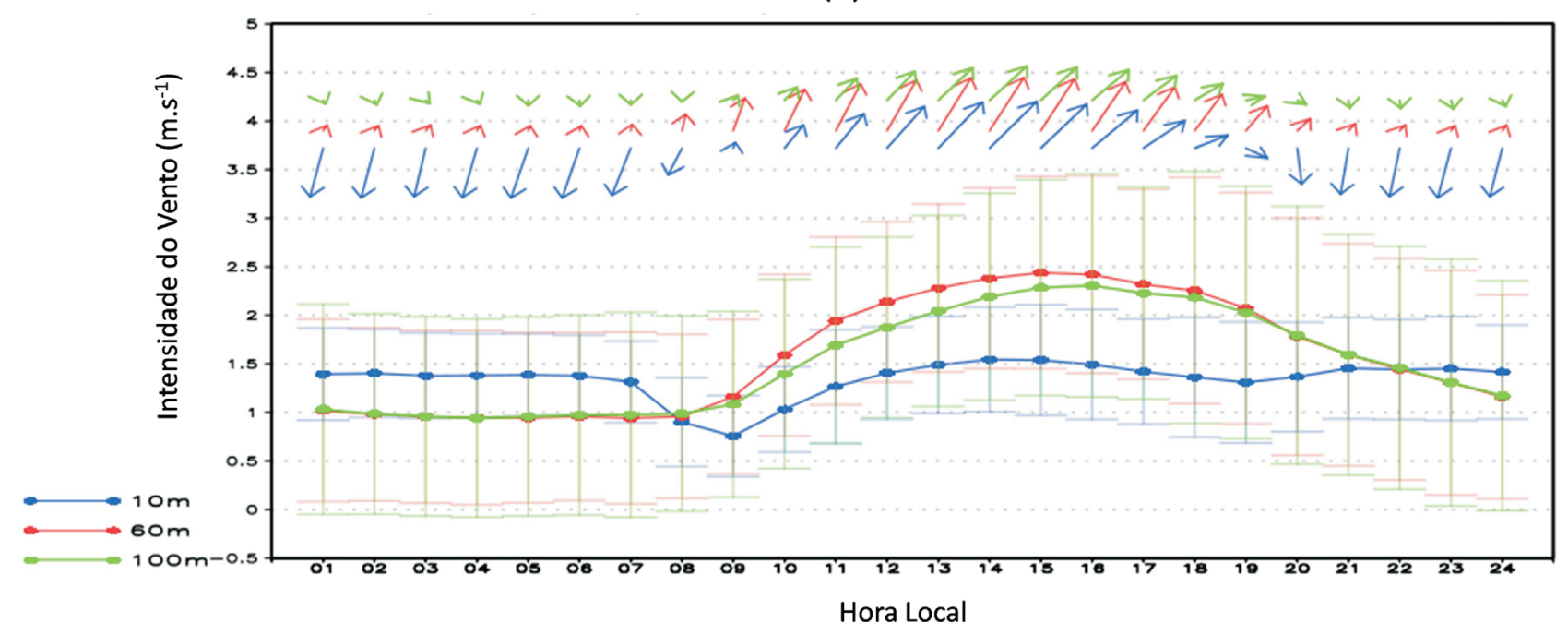

(b) Outono

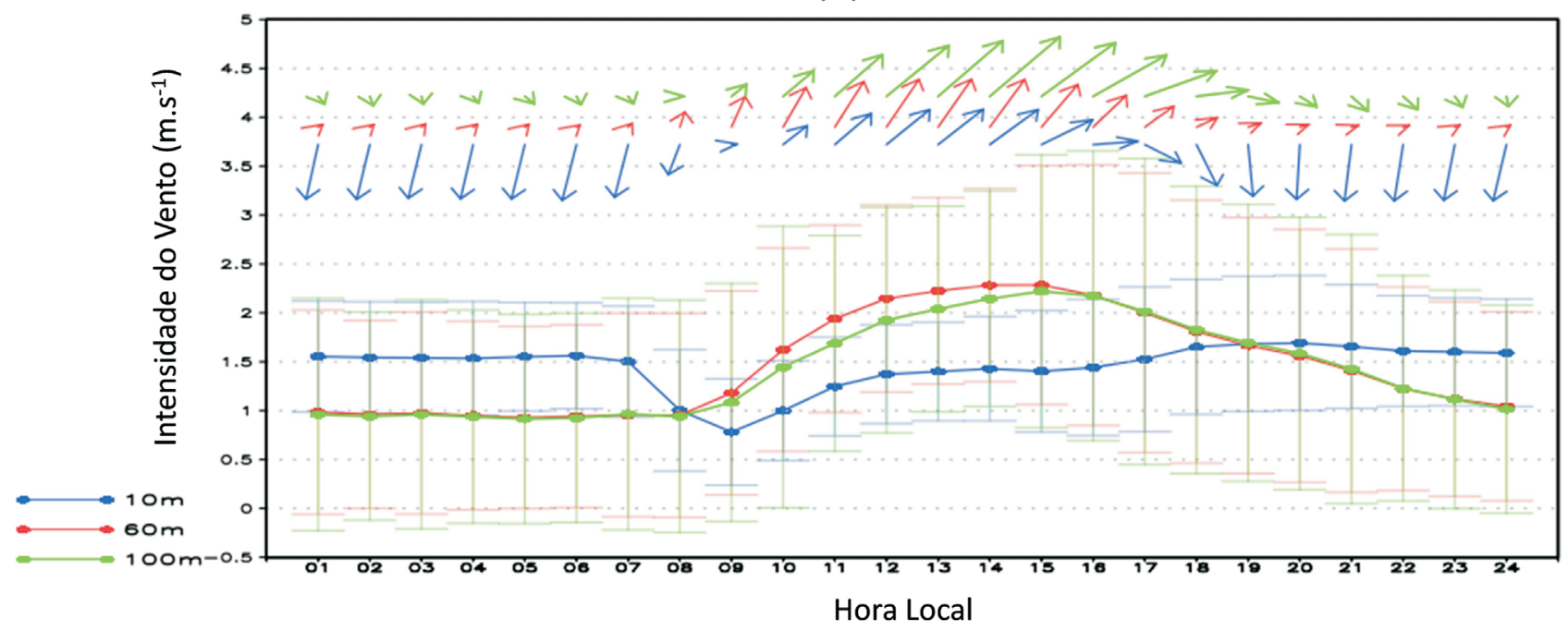

Figura 5 - Intensidade média do vento em m/s (linha), desvio padrão (barra) e direção (setas) para: (a) Torre A 10, 60 e 100 m - verão, (b) Torre A 10, 60 e $100 \mathrm{~m}$ - outono, (c) Torre A 10, 60 e $100 \mathrm{~m}$ - inverno, (d) Torre A 10, 60 e 100 m - primavera. Climatologia do período de janeiro de 2005 a dezembro de 2012 (8 anos). 


\section{(c) Inverno}

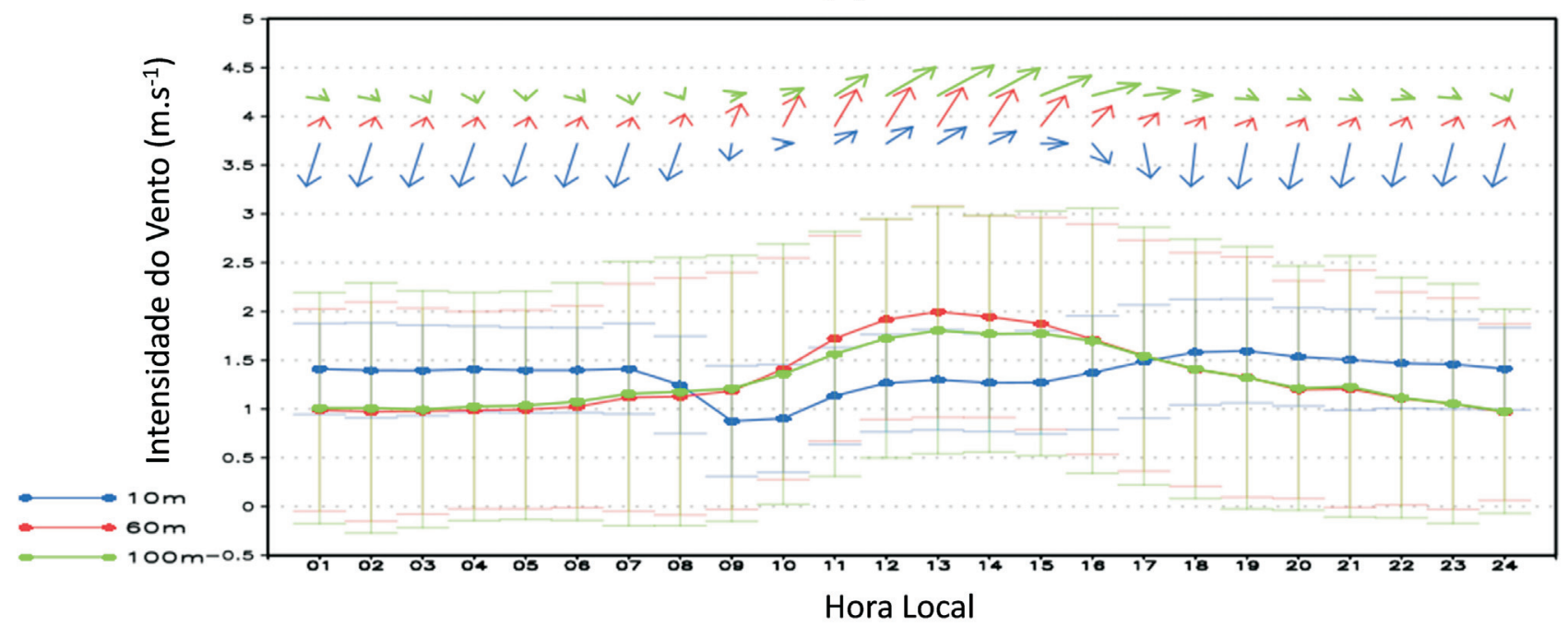

(d) Primavera

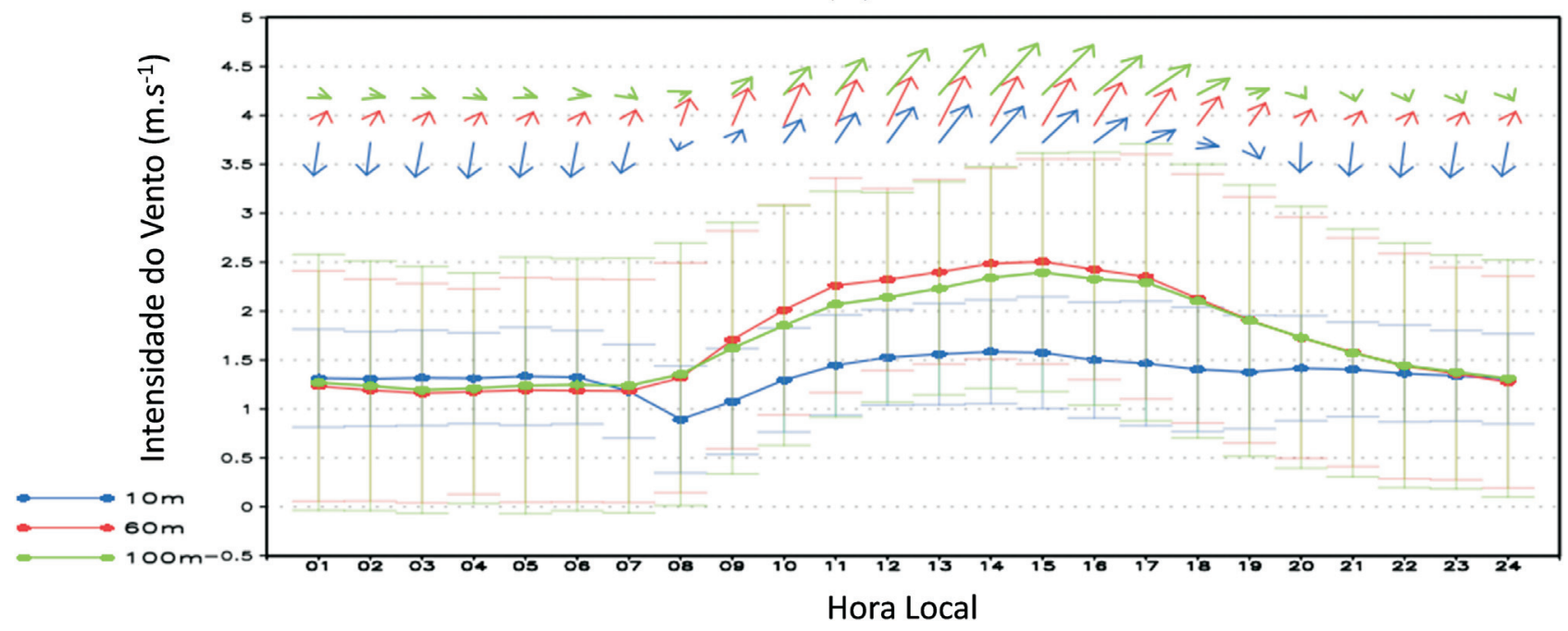

Figura 5 (cont.) - Intensidade média do vento em m/s (linha), desvio padrão (barra) e direção (setas) para: (a) Torre A 10,60 e 100 m - verão, (b) Torre A 10, 60 e $100 \mathrm{~m}$ - outono, (c) Torre A 10, 60 e $100 \mathrm{~m}$ - inverno, (d) Torre A 10, 60 e $100 \mathrm{~m}$ - primavera. Climatologia do período de janeiro de 2005 a dezembro de 2012 ( 8 anos)

Na Fig. 7 são apresentados os gráficos de distribuição de frequência da intensidade do vento nas quatro Torres e durante as quatro estações do ano. Nota-se na Fig. 7 a que no nível de $10 \mathrm{~m}$ a maior frequência de ocorrência ocorre na classe 1,5-2 $\mathrm{m} / \mathrm{s}$, enquanto nos níveis superiores $(60 \mathrm{e}$ $100 \mathrm{~m}$ ) predominam intensidades menores, na classe 0,5-1 m/s. Por outro lado, em relação aos extremos de velocidade do vento, os ventos mais intensos ocorrem em MAM, enquanto as classes de maiores intensidades, ocorrem para os níveis superiores $(60$ e $100 \mathrm{~m})$. Por exemplo, no nível de $100 \mathrm{~m}$ no outono o vento chega a $11,5-12 \mathrm{~m} / \mathrm{s}$, enquanto no nível de $10 \mathrm{~m}$, o vento só atinge a classe $6,5-7 \mathrm{~m} / \mathrm{s}$, o que também ocorre no outono.

Na Fig. 7 b, comparando-se as intensidades dos ventos nas quatro torres observa-se o predomínio de vento na classe $1,5-2 \mathrm{~m} / \mathrm{s}$ e valores extremos ocorrendo predominantemente na Torre $\mathrm{B}$, devido a sua localização mais próxima ao oceano. Os ventos na torre B a $15 \mathrm{~m}$ de altura têm aproximadamente a mesma intensidade dos ventos na Torre A a 100 m (Fig. 7 a).

\subsection{Precipitação}

O ciclo diurno dos totais pluviométricos horários é apresentada na Fig. 8. Nessa figura a média é feita considerando-se todos os dados, inclusive a precipitação igual a zero. Observa-se como esperado a grande magnitude do desvio padrão, principalmente no verão, já que a variável não apresenta distribuição normal. $\mathrm{O}$ desvio padrão é pequeno no inverno, quando também ocorrem em média as menores quantidades de precipitação na região. Durante as 
quatro estações do ano, a precipitação média é mais intensa no final da tarde e durante a noite, coincidindo com o horário da reversão entre as brisas marítima e terrestre. A precipitação média é maior no verão, a seguir no outono, primavera e por último no inverno.

A Fig. 9 apresenta a frequência de ocorrência percentual dos totais pluviométricos horários por estação do ano. Nessa figura considera-se apenas os totais pluviométricos horários superiores ou iguais a $0,25 \mathrm{~mm} / \mathrm{h}$. Nota-se que predomina precipitação fraca (até $4 \mathrm{~mm} / \mathrm{h}$ ) nas quatro estações do ano. Chuvas moderadas (entre 4 e $24 \mathrm{~mm} / \mathrm{h}$ ) e fortes (maior que $24 \mathrm{~mm} / \mathrm{h}$ ) ocorrem predominantemente no verão e outono, com destaque aos registros em MAM.

A Fig. 10 apresenta a frequência de ocorrência da chuva fraca $(>0,25 \mathrm{e}<=4,0 \mathrm{~mm} / \mathrm{h})$, moderada $(>4,0 \mathrm{e}$ $<=24,0 \mathrm{~mm} / \mathrm{h})$ e forte $(>24,0 \mathrm{~mm} / \mathrm{h})$ para cada estação do ano durante a madrugada, manhã, tarde e noite. Os valores

de frequência de ocorrência estão calculados em porcentagem por estação do ano, de forma que a soma das ocorrências de chuva fraca, moderada e forte durante todo o dia para cada estação do ano totalize $100 \%$. Nota-se que a chuva ocorre predominantemente no período noturno durante as quatro estações do ano, independentemente da sua intensidade. Nos demais períodos do dia (madrugada, manhã e tarde) a frequência de ocorrência da chuva é bastante uniforme, exceto a chuva fraca no outono, que predomina na madrugada. Analisando-se apenas a chuva moderada e forte, verifica-se que as chuvas ocorrem preferencialmente no outono e verão, como esperado.

\section{Conclusões}

Neste trabalho elabora-se uma climatologia sazonal de 8 anos das variáveis temperatura do ar, direção e intensi-

\section{(a) Verão}

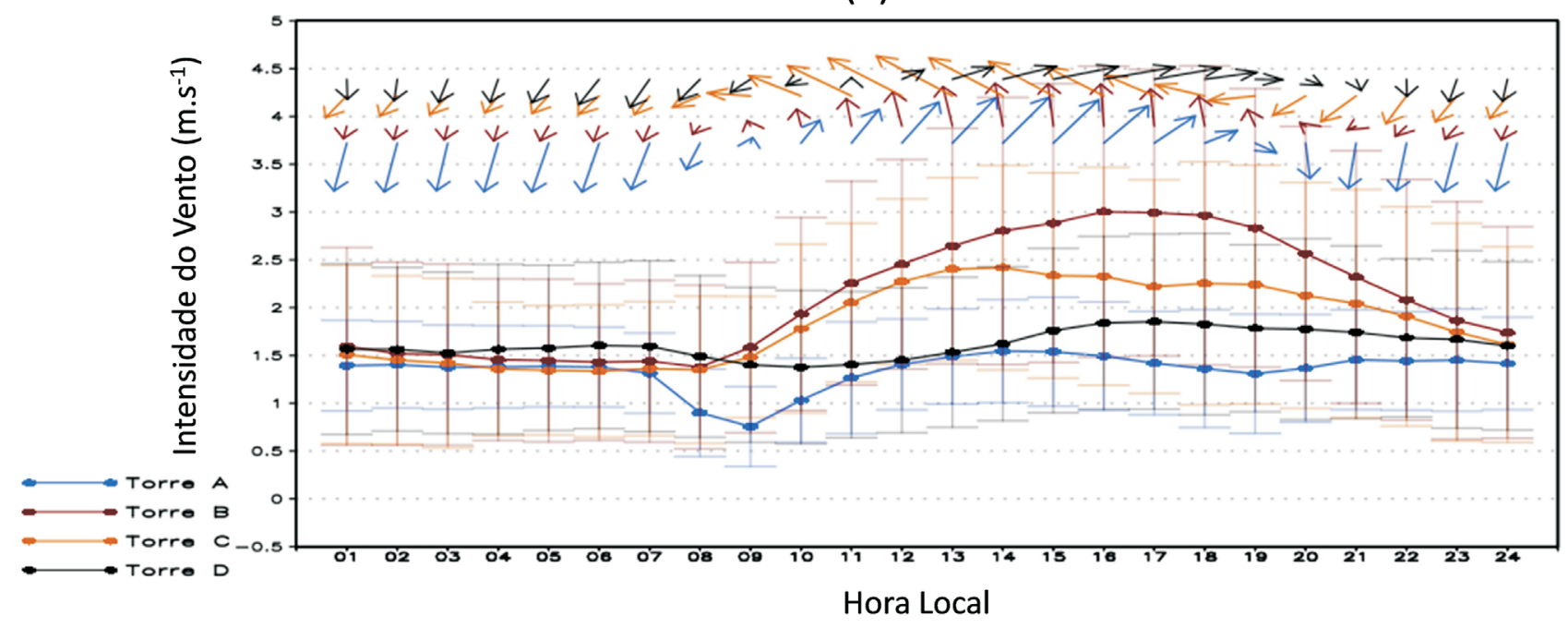

(b) Outono

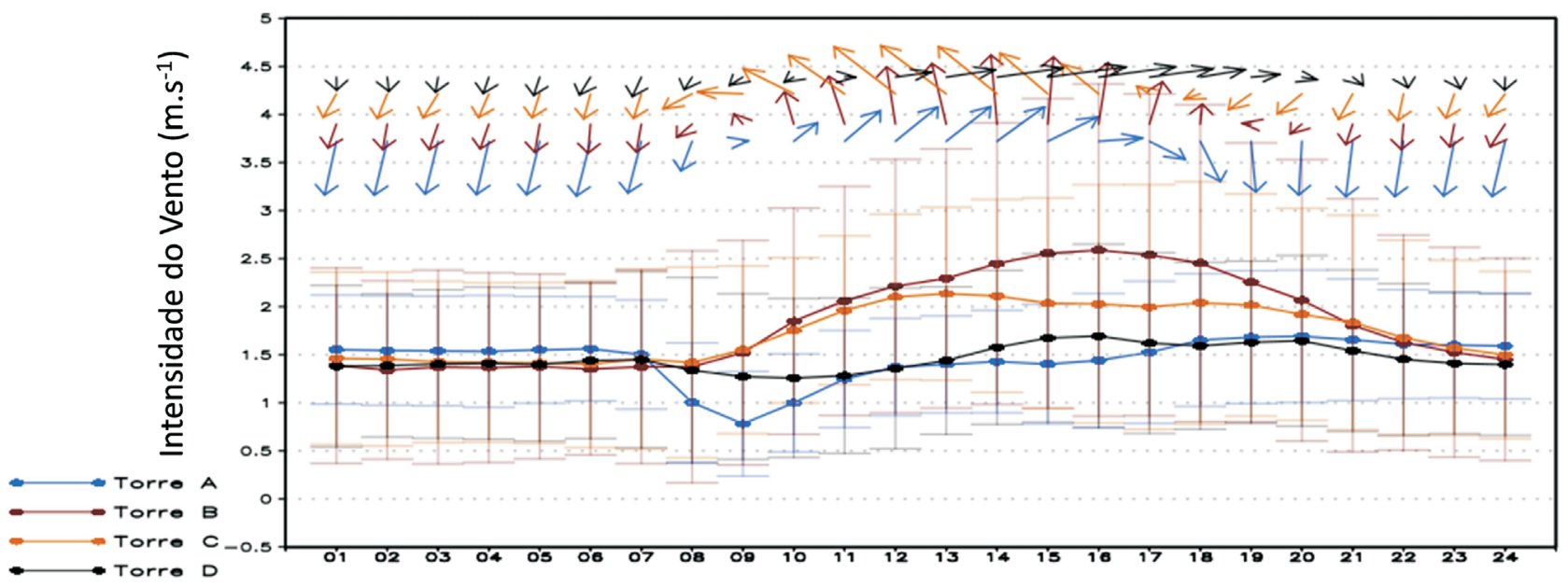

Hora Local

Figura 6 - Intensidade média do vento em m/s (linha), desvio padrão (barra) e direção (setas) para as Torres A 10 m, B, C e D 15 m: (a) verão, (b) outono, (c) inverno e (d) primavera. Climatologia do período de janeiro de 2005 a dezembro de 2012 (8 anos). 


\section{(c) Inverno}

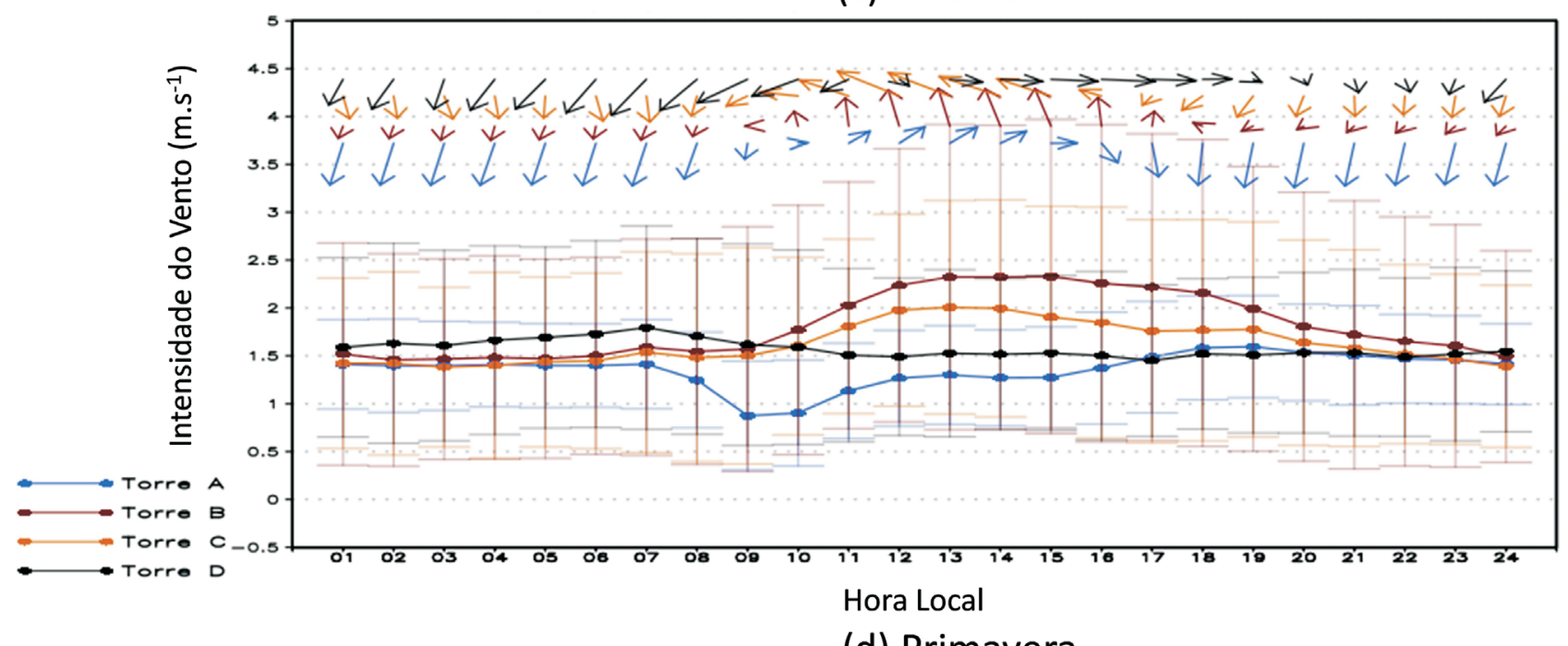

(d) Primavera

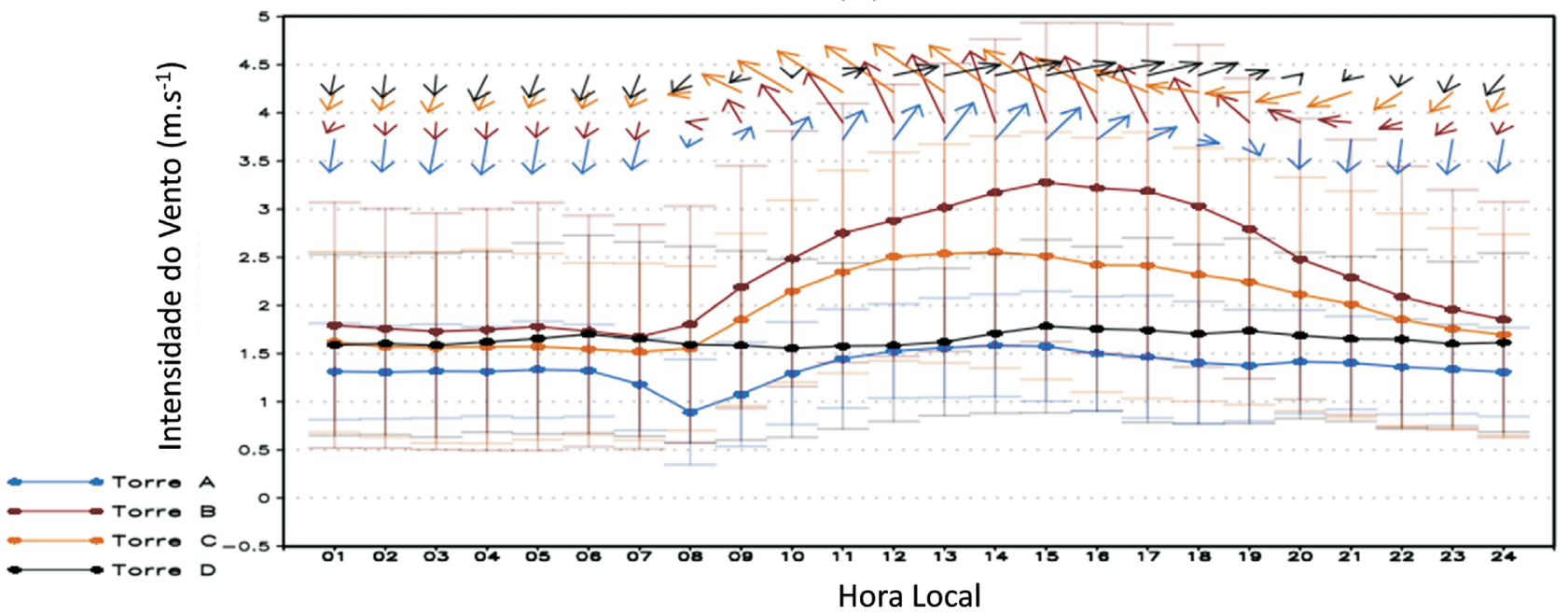

Figura 6 (cont.) - Intensidade média do vento em m/s (linha), desvio padrão (barra) e direção (setas) para as Torres A 10 m, B, C e D 15 m: (a) verão, (b) outono, (c) inverno e (d) primavera. Climatologia do período de janeiro de 2005 a dezembro de 2012 (8 anos).

dade do vento observadas em quatro torres instaladas na região da CNAAA e precipitação. A Torre A é a única torre que mede as variáveis temperatura do ar, direção e intensidade do vento em três níveis de altura $(10,60$ e $100 \mathrm{~m})$. As demais torres $(\mathrm{B}, \mathrm{C}$ e $\mathrm{D})$ registram somente a intensidade $\mathrm{e}$ direção do vento a $15 \mathrm{~m}$ de altura.

Os resultados mostram que os maiores valores da temperatura do ar oscilam entre 26 e $27^{\circ} \mathrm{C}\left(19\right.$ e $\left.20^{\circ} \mathrm{C}\right)$ no verão (inverno) entre os três níveis $(10,60$ e $100 \mathrm{~m})$ de altura da Torre A, ou seja, uma amplitude térmica média anual em torno de $7{ }^{\circ} \mathrm{C}$. As variações de temperatura que ocorrem entre os três níveis de altura são pequenas quando comparadas às variações intersazonais. A amplitude térmica média diária no nível de $10 \mathrm{~m}$, de cerca de $3,0{ }^{\circ} \mathrm{C}$ no verão, é maior do que nos níveis mais elevados, de aproximadamente $1,5^{\circ} \mathrm{C}$, o que ocorre devido a maior eficiência dos processos de troca de calor em camadas mais próximas ao solo. Nesse nível mais baixo $(10 \mathrm{~m})$ a temperatura é em geral mais baixa do que nos demais níveis durante a noite e a madrugada, principalmente no inverno, já que o ar em contato com a superfície é resfriado por condução e por perda radiativa. Durante o dia a temperatura do ar a $10 \mathrm{~m}$ de altura eleva-se acima dos valores encontrados no níveis de 60 e 100 m. Da mesma forma, a redução da temperatura com a altura também é evidente, observando-se que durante todo o ano a temperatura a $60 \mathrm{~m}$ é aproximadamente $0,7^{\circ} \mathrm{C}$ maior do que a temperatura a $100 \mathrm{~m}$ durante todo o dia, o que justifica-se pelo fato da atmosfera ser aquecida por baixo.

Com relação à estabilidade estática da atmosfera predominam condições de estabilidade durante todo o ano na camada mais baixa, entre $60-10 \mathrm{~m}$, característica da inversão de temperatura. Tal estabilidade é interrompida apenas durante o aquecimento diurno, quando a atmosfera torna-se condicionalmente instável (no verão, outono e inverno) ou instável (na primavera). 

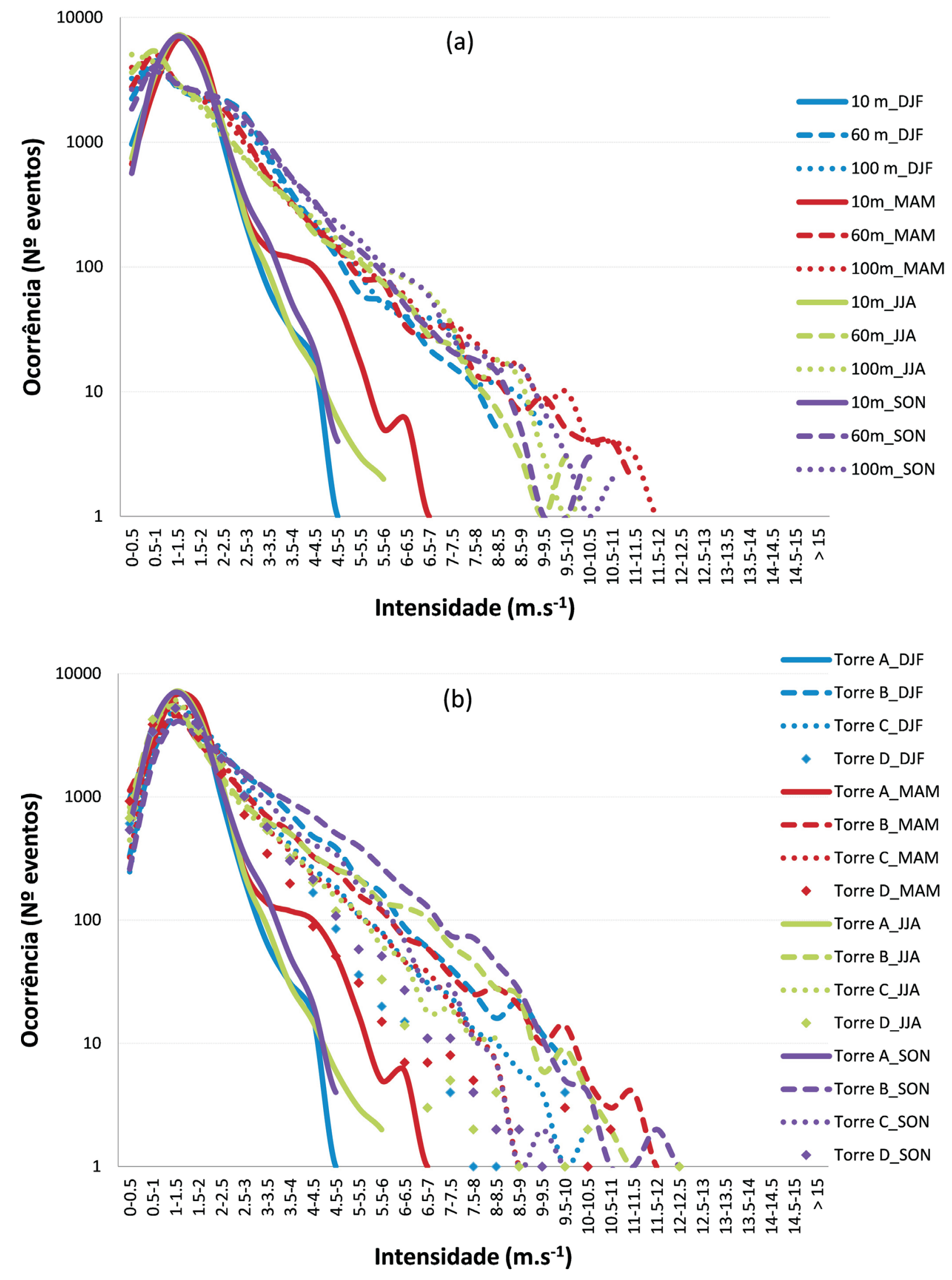

Figura 7 - Distribuição de frequência da intensidade do vento para: (a) Torre A nos níveis 10, 60 e 100 m e (b) Torres A 10 m, B, C e D 15 m. Climatologia do período de janeiro de 2005 a dezembro de 2012 ( 8 anos). 


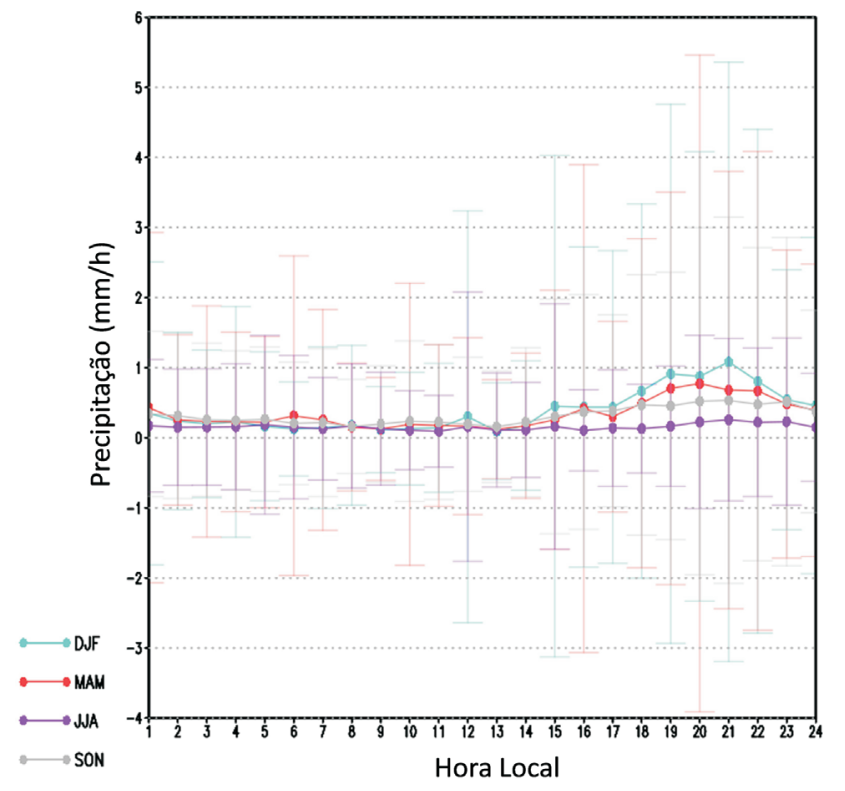

Figura 8 - Ciclo diurno das médias dos totais pluviométricos horários $(\mathrm{mm} / \mathrm{h})$ na região da CNAAA por estação do ano. Climatologia do período de janeiro de 2005 a dezembro de 2012 ( 8 anos).

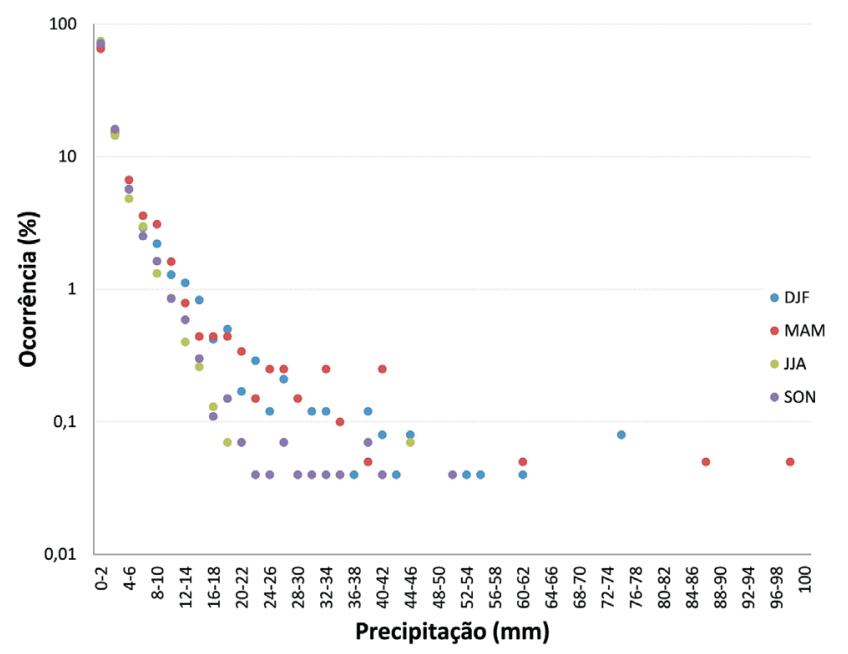

Figura 9 - Distribuição de frequência relativa dos totais pluviometricos horários $(\mathrm{mm} / \mathrm{h})$ para verão (DJF), outono (MAM), inverno (JJA) e primavera (SON). Climatologia do período de janeiro de 2005 a dezembro de 2012 ( 8 anos).

A análise do vento indica a atuação da brisa marítima na área de estudo que se estende até $100 \mathrm{~m}$ de altura, com aumento da intensidade entre 8 e 9 h da manhã, atingindo um máximo em torno de $15 \mathrm{~h}$ e enfraquecendo a seguir. No nível mais baixo $(10 \mathrm{~m})$ destaca-se também a mudança em sua direção, passando de quadrante norte na noite e madrugada para quadrante sul nos períodos da manhã e da tarde. A respeito da distribuição espacial da velocidade do vento, nota-se que no horário de atuação da brisa marítima o vento é mais intenso na Torre B. Nos demais horários do dia as intensidades dos ventos nas quatro torres não são muito distintas.

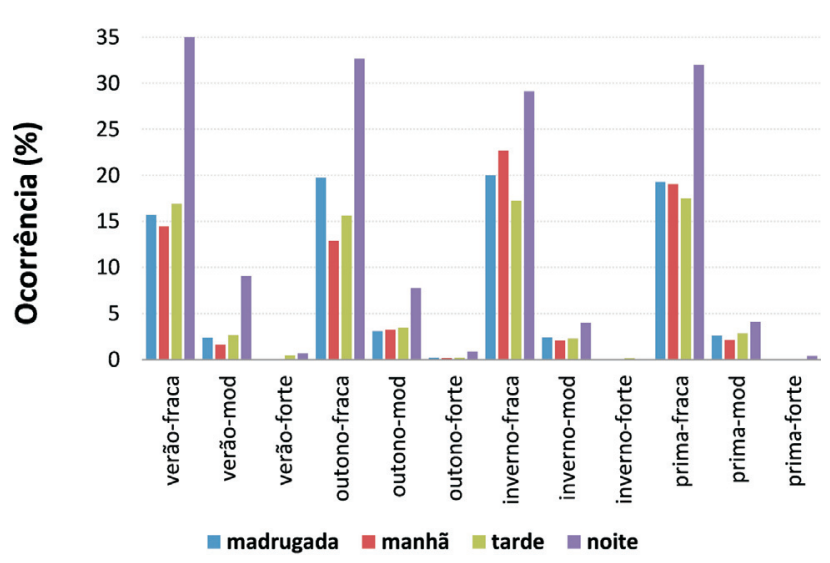

Figura 10 - Frequência de ocorrência percentual da chuva fraca $(0,25$ e $<$ $=4,0 \mathrm{~mm} / \mathrm{h})$, moderada $(>4,0 \mathrm{e}<=24,0 \mathrm{~mm} / \mathrm{h})$ e forte $(>24,0 \mathrm{~mm} / \mathrm{h})$ para o verão, outono, inverno e primavera durante os períodos da madrugada (0-5 h), manhã (6-11 h), tarde (12-17 h) e noite (18-23 h). Climatologia do período de janeiro de 2005 a dezembro de 2012 ( 8 anos).

A precipitação média na região da CNAAA é maior no final da tarde e durante a noite, coincidindo com o horário da reversão entre as brisas marítima e terrestre. A precipitação média é maior no verão, a seguir no outono, primavera e por último no inverno. Como esperado predomina precipitação fraca (até $4 \mathrm{~mm} / \mathrm{h}$ ) nas quatro estações do ano. Chuvas moderadas (entre 4 e $24 \mathrm{~mm} / \mathrm{h}$ ) e fortes (maior que $24 \mathrm{~mm} / \mathrm{h}$ ) ocorrem predominantemente no verão e outono. Com relação a frequência de ocorrência da precipitação ao longo do dia, nota-se que as chuvas ocorrem preferencialmente no período noturno, independentemente de sua intensidade e estação do ano.

\section{Agradecimentos}

Os autores agradecem a Eletronuclear pela cessão dos dados das Torres, ao INPE e ao CNPq pela bolsa PIBIC do primeiro autor.

\section{Referências}

AYOADE, J.O. Introdução a Climatologia para os Trópicos. $11^{\mathrm{a}}$ Ed. Rio de Janeiro. Bertrand Brasil, 332 p, 2006. Tradução Profa. Maria Juraci Zani dos Santos.

DERECZYNSKI, C.P.; JUSTI DA SILVA, M.G.A.; GROSSMAN, K.S. Meteorologia da Bacia do Espírito Santo e parte norte da Bacia de Campos - AGES. Caracterização ambiental regional da AGES. Relatório Técnico, Centro de Pesquisas Leopoldo Américo Miguez de Mello (CENPES). Petrobras. Rio de Janeiro, RJ, Brasil, 2015.

HESS, A.L. Introduction to Theorethical Meteorology. Robert E. Krieger Publishing Company. Flórida. EUA. 363 p, 1959.

KOUSKY, V.E. Pentad Outgoing Longwave Radiation Climatology for the South American Sector. Revista Brasileira de Meteorologia, v. 3, p. 217-231, 1988.

LEÃO, I.L.B.; PEREIRA, J.F. Atividades Desenvolvidas para Complementação dos Estudos Micrometeorológicos do Sítio de Angra dos Reis. Relatório Técnico 551.1 - L 433a, 
Comissão Nacional de Energia Nuclear (CNEN), Rio de Janeiro, RJ, Brasil, 56 p., 1976.

MESINGER, F.; CHOU, S.C.; GOMES, J.L.; JOVIC, D.; BASTOS, P.; BUSTAMANTE, J.F.; LAZIC, L.; LYRA, A.A.; MORELLI, S.; RISTIC, I.; VELJOVIC, K. An upgraded version of the Eta model. Meteorology and Atmospheric Physics. v. 116, n. 3, p. 63-79.

OLIVEIRA, A. Interações entre sistemas frontais na América do Sul e a convecção da Amazônia. INPE-4008-TDL/239. Dissertação (Mestrado em Meteorologia) - Instituto Nacional de Pesquisas Espaciais (INPE), São José dos Campos, SP. 115 p., 1986.

OLIVEIRA JÚNIOR, J.F. Estudo da Camada Limite Atmosférica na Região de Angra dos Reis Através do Modelo de Mesoescala MM5 e Dados Observacionais. Tese (Doutorado em Engenharia Civil) - COPPE/UFRJ, Rio de Janeiro, RJ, Brasil, 272 p., 2008.

OLIVEIRA JÚNIOR, J.F.; PIMENTEL, L.C.G.; LANDAU, L. Critérios de Estabilidade Atmosférica para a Região da Central Nuclear ALMIRANTE ÁLVARO ALBERTO, Angra dos Reis-RJ. Revista Brasileira de Meteorologia, v. 25, n. 2, p. 270-285. 2010.
ROSA, A.N. Estudo de Impacto Ambiental e Relatório de Impacto Ambiental da Unidade 3 da Central Nuclear Almirante Álvaro Alberto (CNAAA) - Angra 3, Eletrobrás Termonuclear S. A., 97 p., 2003.

SATYAMURTI, P.; NOBRE, C.; SILVA DIAS, P.L. South América. Capítulo 3 C, Meteorological Monographs, v. 27, n. 49, p. 119-139, 1988.

SIQUEIRA, J.R.; MARQUES, V.S. Occurrence frequencies and trajectories of mesoscale convective systems over southeast Brazil related to cold frontal and non-frontal incursions. Australian Meteorological Magazine, v. 57, p. 345-357, 2008.

SOARES, P.S. Caracterização da Precipitação na Região de Angra dos Reis e a sua Relação com a Ocorrência de Deslizamentos de Encostas. Dissertação (Mestrado em Engenharia Civil) - COPPE/UFRJ, Rio de Janeiro, RJ, Brasil, 2006.

WALLACE, J.M.; HOBBS, P.V. Atmospheric Science: An Introductory Survey. Second Edition. Academic Press, 505 p, 2006.

All the contents of this journal, except where otherwise noted, is licensed under a Creative Commons Attribution License CC-BY. 